\section{Impact of Beta-Blockade on Exercise Capacity in Subjects with Type 2 Diabetes}

Brassard Patrice, Annie Ferland, Sara Croteau, Lison Fournier, Jean Jobin, Paul Poirier, Centre de recherche de l'Hôpital Laval, Institut universitaire de cardiologie et de pneumologie, Université Laval, Québec, Canada.

Background: Beta-blockers are prescribed to subjects with type 2 diabetes with coronary disease to reduce all-cause mortality. However, this medication reduces exercise capacity in non diabetic individuals. The purpose of this study was to evaluate the impact of betablockade on exercise capacity in diabetic subjects free of coronary disease.

Methods: Ten sedentary men with type 2 diabetes participated in this study. Subjects were treated with oral hypoglycemic agents and/or diet. Exercise capacity was evaluated using an incremental protocol performed on a cycle ergometer. Subjects were evaluated without (WBB group) and following the use of a betablocker (Atenolol $100 \mathrm{mg}$, id) for 5 consecutive days (BB group).

Results: Per study design, subjects were their own control. The BB situation was characterized by a lower resting heart rate (HR) $(54 \pm 4$ vs $74 \pm 12 \mathrm{bpm}$; $P<0.001)$ and a trend toward a lower resting systolic blood pressure (SBP) $(123 \pm 11$ vs $131 \pm 14 \mathrm{mmHg}$; $P=0.1)$ compared to the WBB evaluation. Even with comparable peak workload achieved $(193 \pm 27$ vs $200 \pm 22$ watts), there was a $13 \%$ reduction in relative and absolute values of peak oxygen uptake $(25.8 \pm 3.4$ vs $29.7 \pm 4.1 \mathrm{ml} \cdot \mathrm{kg}-1 \cdot \mathrm{min}-1 ; P<0.05$ and $2.5 \pm 0.5$ vs $2.9 \pm 0.6$ L $\cdot$ min- 1 respectively; $P<0.001)$, a $35 \%$ reduction in peak HR $(110 \pm 9$ vs $169 \pm 14 \mathrm{bpm} ; P<0.001)$ and a $21 \%$ reduction in peak SBP $(167 \pm 24$ vs $211 \pm 20$ $\mathrm{mmHg} ; P<0.001)$ in the BB compared to the WBB situation. Also, the BB situation showed a lower peak minute-ventilation $(97 \pm 15$ vs $120 \pm 24 \mathrm{~L} / \mathrm{min} ; P<0.05)$ compared with WBB.

Conclusion: These results suggest that in subjects with type 2 diabetes free of coronary disease, the use of a beta-blockers impedes cardio-respiratory function at peak exercise beyond compensatory mechanisms leading to a decreased exercise capacity.

\section{Treadmill Running Induces a Detrimental Meta- bolic Adaptation in the Diabetic Mouse}

\author{
Broderick Tom L, Jackie Sennott, Joseph Morrissey, \\ Paul Standley, Department of Physiology, Mid- \\ western University, Glendale, Arizona, USA.
}

Background: Regular exercise is generally recommended for the treatment of type 2 diabetes. Exercise reduces body weight, increases insulin sensitivity, and improves glycemic control. The present study was designed to determine the impact of voluntary wheel and forced treadmill running on the metabolic state in the $\mathrm{db} / \mathrm{db}$ mouse, a model of type 2 diabetes. Our hypothesis is that exercise training improves the metabolic status such that a reduction in body weight, blood glucose and insulin are observed, resulting in improved insulin sensitivity.

Methods: Male diabetic $\mathrm{db} / \mathrm{db}$ mice were assigned to sedentary (DS), voluntary wheel running (DV), and treadmill running (DT) running groups for 12 weeks. Nondiabetic heterozygote littermates served as control $(\mathrm{CN})$.

Results: After 12 weeks of training, DV and DT mice ran a total of $4.24 \pm 0.18 \mathrm{~km}$ and $11.8 \mathrm{~km}$, respectively. Data are expressed as mean \pm SEM for $10-12$ mice in each group. ${ }^{*} P<0.05$ vs $\mathrm{CN}, \dagger P<0.05$ vs DS

\begin{tabular}{|c|c|c|c|c|}
\hline Group & $\begin{array}{c}\text { Body } \\
\text { weight }(\mathrm{g})\end{array}$ & $\begin{array}{c}\text { Glucose } \\
(\mathrm{mmol} / \mathrm{L})\end{array}$ & $\begin{array}{c}\text { Insulin } \\
(\mathrm{microU} / \mathrm{ml})\end{array}$ & QuickI \\
\hline CN & $26 \pm 0.4$ & $6.9 \pm 0.2$ & $15 \pm 2$ & $0.31 \pm 0.06$ \\
DS & $43 \pm 2 *$ & $37.4 \pm 1.5 *$ & $104 \pm 23 *$ & $0.22 \pm 0.03 *$ \\
DV & $37 \pm 2 * \dagger$ & $20.4 \pm 2.9 * \dagger$ & $173 \pm 39 *$ & $0.21 \pm 0.05 *$ \\
DT & $41 \pm 1 *$ & $23.9 \pm 1.6 *$ & $250 \pm 5.7 * \dagger$ & $0.20 \pm 0.05^{*}$ \\
\hline
\end{tabular}

Conclusions: Voluntary exercise training is beneficial in reducing body weight and blood glucose in the $\mathrm{db} /$ $\mathrm{db}$ mouse, but this effect is minor. Forced treadmill running, however, did not improve body weight, blood glucose and the hyperinsulinemic state remained. These results suggest that forced treadmill exercise training may actually worsen the metabolic state in this model of diabetes. 